\title{
ARTIGO
}

CO https://doi.org/10.22481/praxisedu.v16i37.6169

\section{"CUIDADO COM A LEITURA": LIVROS E LEITURA NA COLUNA JORNALÍSTICA ENSINO E EDUCAÇÃO NO CEARÁ DOS ANOS 1944 A 1950}

"CARE OF READING": BOOKS AND READING IN THE JOURNALISTIC COLUMN TEACHING AND EDUCATION IN CEARÁ FROM THE YEARS 1944 TO 1950

\author{
“CUIDADO CON LA LECTURA": LIBROS Y LECTURA EN LA COLUMNA \\ PERIODÍSTICA ENSEÑANZA Y EDUCACIÓN EN EL ESTADO DEL CEARÁ DE LOS
}

AÑOS 1944 A 1950

Manuelle Araújo da Silva

Universidade Federal da Paraíba - Brasil

Fabiana Sena

Universidade Federal da Paraíba - Brasil

Mariza Silva de Araújo

Instituto de Educação Superior Presidente Kennedy - Brasil

Resumo: O presente trabalho buscou dar visibilidade às orientações sobre livro e leitura pelo Prof. Antônio Coelho Sampaio, na coluna jornalística Ensino e Educação, publicadas, no periódico Gazeta de Notícias, do estado do Ceará, no período de 1944 a 1950. Para tanto, o conteúdo desta coluna não foi tomado como discursos de verdade, por considerar o referido periódico - suporte em que foi publicada - lugar do diálogo, do debate, das polêmicas, de modo a representar um discurso que deixou vestígios, mostrando as relações entre o jornal e aqueles a quem era destinado. Nesse sentido, tomouse como referência teórico-metodológica a concepção de Roger Chartier sobre representação, levandose em conta que cada série de discursos deve ser compreendida em sua singularidade, ou seja, em seus lugares de produção, de circulação e apropriação. Neste trabalho, verificamos que há uma preponderância de discursos acerca das leituras pretensamente proibidas - mais valoradas como más, vis e amorais do que propriamente orientações sobre o que se deveria ler.

Palavras chave: Jornal, Livros, Educação, Professor.

Abstract: The present work sought to give visibility to the orientations about book and reading by Prof. Antônio Coelho Sampaio, in the journal Education and Education, published in the periodical Gazeta de Notícias, in the state of Ceará, from 1944 to 1950. For this reason, the contents of this column were not taken as real speeches, journal - a medium in which it was published - a place of dialogue, debate, controversy, in order to represent a discourse that left traces, showing the relations between the newspaper and those to whom it was destined. In this sense, Roger Chartier's conception 
of representation was taken as a theoretical-methodological reference, taking into account that each series of discourses should be understood in its singularity, that is, in its places of production, circulation and appropriation. In this work, we find that there is a preponderance of discourses about the supposedly forbidden readings - more valued as bad, vis and amoral than properly orientations on what one should read.

Key words: Newspaper, Books, Education, Teacher.

Resumen: En el presente trabajo se buscó dar visibilidad a las orientaciones sobre libro y lectura por el Prof. Antônio Coelho Sampaio, en la columna periodística Enseñanza y Educación, publicadas en el periódico Gazeta de Notícias, del estado del Ceará, en el período de 1944 a 1950. Para esto, el contenido de esta columna no fue tomado como discursos de verdad, por considerar el referido periódico - el suporte en que fue publicada - lugar del diálogo, del debate, de las polémicas; de modo a representar un discurso que dejó vestigios, mostrando las relaciones entre el diario y aquellos a quien era destinado. En este sentido, se tomó como referencia teórico-metodológica la concepción de Roger Chartier sobre representación, admitiendo que cada serie de discursos deber ser comprendida en su singularidad, es decir, en sus lugares de producción, de circulación y apropiación. En este trabajo, verificamos que hay una preponderancia de discursos acerca de las lecturas pretensamente prohibidas - pero más valoradas como malas, vis y amorales que propiamente orientaciones sobre lo que se debería leer.

Palabras clave: Diario, Libros, Educación, Profesor.

\section{Introdução}

Este trabalho tem como objetivo identificar as orientações sobre livro e leitura pelo Prof. Antônio Coelho Sampaio, na coluna jornalística Ensino e Educação, publicadas no periódico Gazeta de Notícias, do estado do Ceará, no período de 1944 a 1950. Com tal propósito, questionamos de que maneira o livro, considerado como objeto cultural, foi abordado pelo professor Antônio Coelho Sampaio, na coluna jornalística em análise. O que poderia significar, no período em exame, a existência de uma coluna semanal sobre educação, em um jornal de grande circulação? É necessário explicitar que os jornais são artefatos culturais que, apesar de possuírem linhas editoriais, priorizam o interesse do público leitor, com vistas a aumentar a sua vendagem. A partir dessa premissa, é possível inferir que a temática da educação era considerada como um dos "assuntos palpitantes", como se dizia na época. Em certa medida, configurava-se como uma possível forma de atualização de leituras e opiniões para os professores e indivíduos interessados na temática instrutiva e ou moralizante. 
Toma-se como referência teórica Chartier (1999, p. 09 e 13) e seu conceito de representação. Assim, considera-se que "toda obra está ancorada nas práticas e nas instituições do mundo social". Além disso, também se entende que "as formas produzem sentidos e que um texto, estável por extenso, passa a investir-se de uma significação e de um status inéditos". Ainda de acordo com esse autor, cada série de discursos deve ser compreendida em sua singularidade, ou seja, em seus lugares de produção, de circulação e apropriação.

No que diz respeito à fonte de pesquisa imprensa, no Ceará dos 1940, os jornais eram os principais veículos de comunicação e a Gazeta de Notícias destacava-se como um dos mais populares de Fortaleza. Fundado por pelo jornalista Antônio Luís de Drummond Miranda, em 1927, seus editores declaravam esse jornal como Diário Matutino Independente.

Neste nosso estudo, esclarecemos que os conteúdos manifestos na coluna Ensino e Educação não serão tomados como discursos de verdade, por considerar o referido periódico - suporte em que foi publicada a coluna em questão - lugar do diálogo, do debate, das polêmicas, de modo a representar um discurso que deixou vestígios, mostrando as relações entre o jornal e aqueles a quem era destinado.

\section{Situando o jornal (Gazeta de Notícias), a coluna (Ensino e Educação) e o seu autor (Antônio Coelho Sampaio)}

Gazeta de Notícias: diário matutino e independente foi fundado em 1927, por Antonio Drummond ${ }^{1}$, teve sua primeira publicação em 10 de julho de 1927, com 16 páginas, tendo como diretor geral Ruy Costa Sousa e a direção comercial chefiada por Camerino Teixeira. Verificou-se, na delimitação temporal desta pesquisa, que esse periódico buscou afastar-se do caráter político-partidário conforme pressupõe o seu sub-título. Essa representação de si mesmo também deve ser problematizada, na medida em que esse diário publica eminentemente editoriais moralistas, que buscavam promover a brasilidade, a ordem, o civismo, a religião cristã nos indivíduos. Embora não se tenha declarado como um diário de orientação católica - como fez o jornal O Nordeste, no mesmo período, subsidiado pela Arquidiocese de Fortaleza -, o seu posicionamento deve ser compreendido nas sutilezas do não dito.

\footnotetext{
1 Antônio Luís Drumond de Miranda era pernambucano, de Recife; nasceu em 30/11/1872 e radicou-se em Fortaleza, exercendo a política, a advocacia e o jornalismo. Foi assassinado, em seu local de trabalho por Virgílio Gomes de Oliveira, juiz municipal. Disponível em http://portal.ceara.pro.br. Acesso: 16/04/2019.
} 
Além das considerações acima, outra possível explicação para ser visto como um jornal independente pode se dar pela não inclusão na rede nacional dos Diários Associados, de Assis Chateaubriand, em contraste com muitos jornais cearenses contemporâneos que a essa rede aderiram. Sob outra perspectiva, o termo independente também pode ser interpretados como uma das formas pela qual o periódico se apresentava aos seus leitores: a favor do acolhimento de várias opiniões sobre um mesmo assunto ou campanhas de vários partidos, por exemplo.

No tempo de circulação da coluna, o diretor superintendente era Antonio Drummond Filho; a proprietária, sua mãe, era a viúva de Antonio Drummond. A redação, administração e oficina se concentravam em um mesmo prédio, localizado na rua Senador Pompeu, 789. As assinaturas variavam de valores conforme o tipo: anual - 100, 00 cruzeiros; semestral - 50,00 cruzeiros; número avulso - 0,40 centavos; número atrasado - 1,00 cruzeiro. Esse jornal contava com um correspondente no Rio de Janeiro - A. Herrera \& Cia. Ltda. (GAZETA DE NOTÍCIAS, 08/01/1946).

No que se refere à coluna Ensino e Educação, a primeira foi publicada em janeiro do ano de 1944, esta se propunha a manter uma periodicidade semanal; no entanto, observouse uma irregularidade entre os intervalos de publicação do jornal, consequentemente da coluna, de modo que o último número da coluna data de janeiro de 1950.

Na maioria de seus números, a coluna Ensino e Educação ocupava 1/3 da página do jornal Gazeta de Notícias. Conforme se pode constatar pela Figura 1, os aspectos de diagramação da coluna em relação à página do jornal também demonstram a presença de publicidades e de outros artigos que compunham a mesma página. É interessante observar que esses outros editoriais diferenciavam, às vezes, em relação à temática instrutiva, mas, em algumas ocasiões, versavam sobre um mesmo tema. 
Figura 1 - Preponderância do assunto Ensino e diagramação propícia a outras publicidades

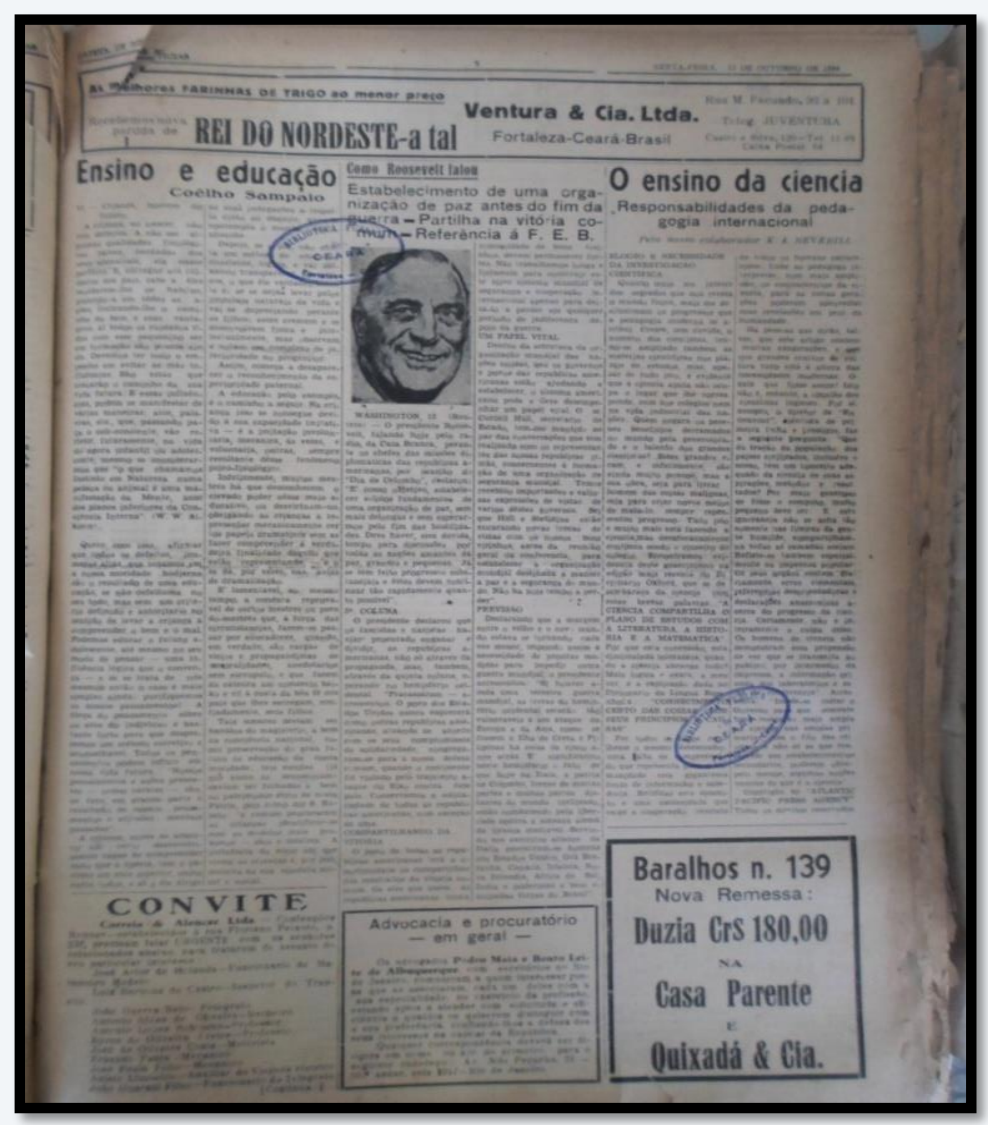

Fonte: GAZETA DE NOTÍCIAS. Fortaleza, p. 5, 13 out.1944.

Observem-se os títulos de outras colunas do mesmo jornal: Odontologia e Saúde ${ }^{2}$, Lições de Civismo ${ }^{3}$, Em Torno da Crise ${ }^{4}$ e Educação: O Problema Vital para a Paz ${ }^{5}$. Problemas odontológicos, crise, paz, educação parecem despertar interesse contínuo nas pessoas, por afetarem - ainda que uns mais e outros menos - seus cotidianos. A partir dessa observação, é possível adotar como hipótese que a coluna Ensino e Educação poderia ser um artifício de atração do leitor professor ou outros agentes da educação ao jornal Gazeta de Notícias.

\footnotetext{
${ }^{2}$ Assinadas pelo Prof. Paulo Firmeza, aliava as instruções práticas da educação sanitária ao incentivo ao patriotismo e aos princípios da moral cristã.

${ }^{3}$ A autoria dessa seção é de Pereira e Silva. Até pelo seu título, nota-se que o objetivo é ensinar, aos seus leitores, definições de símbolos e conceitos cívicos bem como as datas e os vultos da História do Brasil, sob o viés factual e político. São artigos que buscavam despertar uma consciência cívica - que também foi título de um editorial da Gazeta de Notícias - nos cidadãos brasileiros, incitando o amor à Pátria.

${ }^{4}$ Seção que objetivava expor a origem dos problemas sociais do período, assinadas por Heitor Cavalcanti, no jornal Gazeta de Notícias. Eventualmente falava-se sobre assuntos do setor educacional.

${ }^{5}$ Coluna publicada a partir do fim de 1944, discutindo mundialmente as relações entre Educação e Segunda Guerra Mundial no jornal Gazeta de Notícias.
} 
O professor Coelho Sampaio começou a publicar, no jornal, com 23 anos de idade, ainda estudante do curso de Ciências Econômicas da Faculdade de Ciências Econômicas do Ceará. Foi fundador e diretor do Instituto Escolar São Raimundo, uma escola de pequeno porte, até 1954, ano em que se mudou para a cidade de Vitória, no Espírito Santo.

No ano de 1946, foi eleito presidente da União Estadual dos Estudantes (UEE), sendo líder estudantil no IV Congresso Estadual dos Estudantes. Conforme Ramalho (2002), a UEE foi um relevante movimento estudantil composto por estudantes do ensino superior. Considera-se que esse momento de liderança estudantil foi um dos motes que lhe concedeu maior destaque na imprensa cearense, constando recorrentes matérias enaltecendo a sua figura. ${ }^{6}$

O conjunto dos textos se materializava por meio da escrita epistolar de Antônio Coelho Sampaio, pois, ao final de cada artigo, constava o nome da cidade onde as cartas tinham sido redigidas (Fortaleza), seguida de uma data precedente ao dia da publicação. Um dado a observar é que, nas colunas seguintes, por vezes, constavam notas de erros de transcrição.

Essa estratégia discursiva adotada por Antônio Coelho Sampaio estabelece vínculo entre o íntimo e o público. Elementos como a escrita em primeira pessoa, objetivavam construir proximidade com o leitor, demarcando, concomitantemente, o lugar de sua fala no jornal Gazeta de Notícia e da sua autoria.

De acordo com Antonio Coelho Sampaio, para ser professor, seria necessário ter vocação, ser paternal, se dedicar ao estudo de conhecimentos científicos de diversas áreas relacionadas à Educação bem como à religião, conforme se pode ver no fragmento ${ }^{7}$ abaixo, retirado do texto de sua autoria Quem deve ser mestre:

Assim, pela elevação com que se apresenta, a carreira do magistério é a que maiores e melhores tendências se exige de quem deve ser mestre. Para ser mestre é necessario, antes de tudo, a vocação. Porque nenhum, que aspire a abraçar esta nobre profissão, poderá ser verdadeiramente um mestre se não tiver sido primeiro aprendiz. E a sua dedicação ás crianças deve ser completa e paternal. (...) Mas, o aluno-mestre precisa, antes de mais nada, ter conhecida dedicação ao estudo da Psicologia, Pedagogia, Antropologia, Metodologia, Didática, Logica, E'tica e Religião, afora as outras ciências mais ligadas ao estudo da Natureza. (SAMPAIO, 1946, p. 1 do suplemento).

\footnotetext{
${ }^{6}$ Conforme Braulio Ramalho, a data de fundação da UEE é de 13/12/1942, pouco depois da ocasião em que Raimundo Ivan, credenciado como delegado da UNE, convocou um Congresso Estadual de Estudantes. Essa assembleia foi presidida pelo renomado Antônio Girão Barroso, na Escola Normal Justiniano de Serpa, em 27/11/1942.

7 Todas as transcrições manterão o padrão de escrita original dos documentos da época, sem interferência dos autores deste artigo.
} 
Antonio Coelho Sampaio apresentava em sua seção jornalística quais os indivíduos que ele considerava serem aptos ao labor docente, de acordo com seus ditos valores e predicados. Tratava-se, pois, de deliberar, em sua coluna, as qualidades necessárias para se compor um perfil do que seria um professor dotado de méritos na época.

É relevante ressaltar, entretanto que, no tocante ao Ceará, a intenção pioneira de se construir uma escola cuja principal finalidade fosse formar professores de primeiras letras data de 1837, no governo de José Martiniano Pereira de Alencar. A criação efetiva do que seria uma Escola Normal do Ceará somente aconteceu, contudo, quase 50 anos depois da data acima citada, em 1884, no governo de Sátiro de Oliveira Dias, como instituição para se formarem professoras primárias (SILVA, 2002). Em período concomitante aos discursos de Coelho Sampaio na imprensa cearense, nos anos 1940, existia a Escola Normal Justiniano de Serpa, que, no final da década, passou a funcionar com o nome de Instituto de Educação do Ceará, pelo Decreto-Lei n ${ }^{\circ}$ 2.007, de 07 de fevereiro de 1947, ainda como instituição formadora de professores (SILVA, 2009).

Assim sendo, desde o século XIX, perpassando, portanto, o período de circulação da coluna Ensino e Educação nos anos 1940, havia no Ceará um lugar específico para se ponderar a problemática da formação de professores. Pressupõe-se, com auxílio da pesquisa documental, que não há uma vinculação aparente entre o discurso jornalístico de Coelho Sampaio sobre a profissão docente e a Escola Normal de Fortaleza. Parece haver, então, por parte do autor, uma tentativa de construção de um discurso individual, buscando arquitetar, para si, uma legitimação de fala auto-centrada em sua personalidade.

Seus posicionamentos educacionais eram em forma de ensinamentos a serem seguidos pelos leitores, fossem eles professores, pedagogos ou pais de crianças e adolescentes.

Antônio Coelho Sampaio não relaciona a sua fala com nenhuma categoria de ensino, embora tenha existido uma maior recorrência de colunas cujo assunto eram as questões próprias do infante e do Ensino Primário.

Um ponto importante para se refletir acerca das relações entre os escritos da seção e a sua autoria, do prof $^{\circ}$ Antônio Coelho Sampaio, é que não eram sucessivamente as mesmas informações que acompanhavam a sua assinatura. Por vezes, constava que Sampaio era apenas professor, em outras ocasiões, destacava-se o seu posto de Diretor do Instituto São Raimundo (um pequeno colégio que ele criou e dirigiu naquele período) e, em outras vezes, constava a profissão de jornalista junto ao seu nome. Compreende-se que é relevante observar 
os usos de legitimação dos conteúdos que eram veiculados, a partir de diferentes lugares institucionais que o autor ocupava.

O uso dessa visibilidade social, do espaço colunar fixo utilizado por Coelho Sampaio, se processou de variadas formas. Por meio de um chamado público à comunidade docente, na coluna Ensino e Educação, por exemplo, criou-se uma Associação Cearense de Estudos Pedagógicos (ACEP), tentou-se fundar um Instituto de Pesquisas Econômicas e pediram-se votos políticos. Eram comuns as solicitações como "Daqui desta coluna, peço [...]". Desse modo, esta seção também pode ser considerada um lugar social, um lugar de fala.

Um dos muitos temas abordados por Antônio Coelho Sampaio foi sobre os livros e a leitura, objeto de interesse deste estudo. Esse assunto foi abordado pelo autor de duas formas: como reclame da classe professoral, no formato de denúncia, no sentido de esses profissionais não disporem de bibliotecas públicas e não terem acesso ao artefato livro, considerado como dispendioso; a outra postulava orientações de leitura, apontando os livros que divulgariam conteúdos vis, segundo as referências de uma lógica moralizante do autor.

\section{Reclames de uma classe: o acesso aos livros e à leitura}

Os livros e a leitura se apresentaram de maneira sobressalente na coluna Ensino $e$ Educação aos reclames dos professores particulares. Representando esse segmento de classe, por ser fundador e diretor de um pequeno estabelecimento escolar, em artigo intitulado $O$ Problema do Professor Particular, Sampaio afirma:

Procurei demonstrar, então, quanto precisa gastar o professor para estar em contacto permanente com o progresso científico, adquirindo obras para atualizar seus conhecimentos. E, do mesmo modo, quanto percebe, em troca de tantos sacrificios, em viagens a pé, sob o sol ardente ou a chuva repentina, ou, ainda, gastando as ultimas economias nos elevados preços dos transportes coletivos. (SAMPAIO, 1950, p. 3)

A dificuldade de acesso aos livros para atualizar seus conhecimentos ou falta de tempo e condições de locomoção para ir à Biblioteca Pública bem como deslocar-se entre vários estabelecimentos de ensino, a fim de conseguir mais turmas para aumentar seu ordenado, são algumas das principais reinvindicações dos professores particulares nesse período. Em outro escrito publicado na coluna Ensino e Educação, é possível compreender como o jornal se configurou como um meio para expressar - ou mesmo denunciar, em moldes de manifesto - situações sofríveis da classe. 
Em relação à Biblioteca Pública da cidade, outra denúncia publicada, em 1946, no mesmo jornal partiu da Professora Fernanda Brito, do Centro Cultural José do Patrocínio, ao fazer a seguinte comparação:

No Chile, os professores ganham o duplo dos do Brasil. Na América, há os que possuem nada menos de 3.000.000 volumes nas suas bibliotecas, sem entretanto terem comprado um só volume. E... os nossos mestres além de lutarem com grande dificuldade de incompreensão do meio, ainda tem de resolver as suas questões monetárias. No Ceará, há quase um ano que a biblioteca publica acha-se fechada. Por que? Não sabemos. E os nossos professores precisam ir ler livros didáticos atendendo a necessidade das novas reformas por cima de reformas que atualmente presenciamos no Brasil. (BRITO, 1946, p. 3).

A partir de denúncias como a do Prof. Antonio Coelho Sampaio, endossada pela profa. Fernanda Brito, é possível notar uma comunidade de leitores insatisfeita com a falta de artefatos escolares na cidade, os quais não atendiam a suas demandas e, em especial à melhoria do ensino da época. Entre esses artefatos, os livros. Reivindicava-se aquisição e acesso a esse material.

A dificuldade em acessar obras necessárias à atualização do conhecimento pedagógico se deu na fala da professora através de duas principais vertentes: 1) Uma crítica mais contundente ao Estado, por cercear as possibilidades leitoras dos fortalezenses na época, fechando a Biblioteca Pública sem maiores informações sobre tal procedimento ou prazos de reabertura; e 2) Uma crítica mais geral à falta de disponibilizações/doações de livros educacionais (por parte de Editoras, por exemplo), para compor o que se desejava, ou seja, que cada professor pudesse dispor de uma biblioteca pessoal, para consultas e aprofundamentos nas temáticas do ensino.

Ao fim do trecho em análise, a Profa. Fernanda Brito destaca que uma das problemáticas mais acentuadas que os professores daquele período enfrentavam, por conta das limitações de acesso a livros, seria a dificuldade de se atender à demanda de atualização docente que as reformas educacionais de então exigiam. Embora não tenha citado nominalmente, as reformas às quais Fernanda Brito se referiu no artigo citado provavelmente diziam respeito às Leis Orgânicas do Ensino, também chamadas de Reforma Capanema, a qual consistia em uma série de Decretos-Lei expedidos entre os anos de 1942 a 1946, tendo como enfoque a reestruturação do ensino profissional, industrial e na reformulação do ensino comercial. (SCHWARTZMAN; BOMENY; COSTA, 2000). 
A leitora/autora desenvolve uma crítica à disparidade de ritmos entre as reformas educacionais (abundantes e numerosas) e o acesso à leitura (parco e dificultoso). Torna-se relevante, então, observar a perspectiva crítica de uma professora que vivenciou os numerosos decretos-lei constitutivos da Reforma Capanema, na década de 1940, travando um embate com visões mais oficiosas do Ensino, por meio das reformas expedidas pelo Ministério da Educação e Saúde.

Na imprensa, Fernanda Brito, leitora-autora, também expôs outras incongruências existentes entre as muitas responsabilidades exigidas ao mestre e ao seu salário. Aspectos como a dificuldade em pagar até mesmo a quantia exigida como esmola na missa, o desconto no ordenado mensal por faltas atribuídas às doenças bem como as altas cifras necessárias para cumprir-se a exigência do uso de vestimentas consideradas condignas aos mestres descortinam as dificuldades encontradas por esses sujeitos que laboravam no magistério e a forma com que os parcos ordenados impactavam suas vidas.

Ao observar na Figura 2 o traje usado pela professora, em foto publicada na Gazeta de Notícias, é possível ter pistas do que poderia significar os trajes alinhados, exigidos aos professores como expressão de sua moralidade.

Figura 2 - Artigo publicado na Gazeta de Notícias, sob autoria de Fernanda Brito

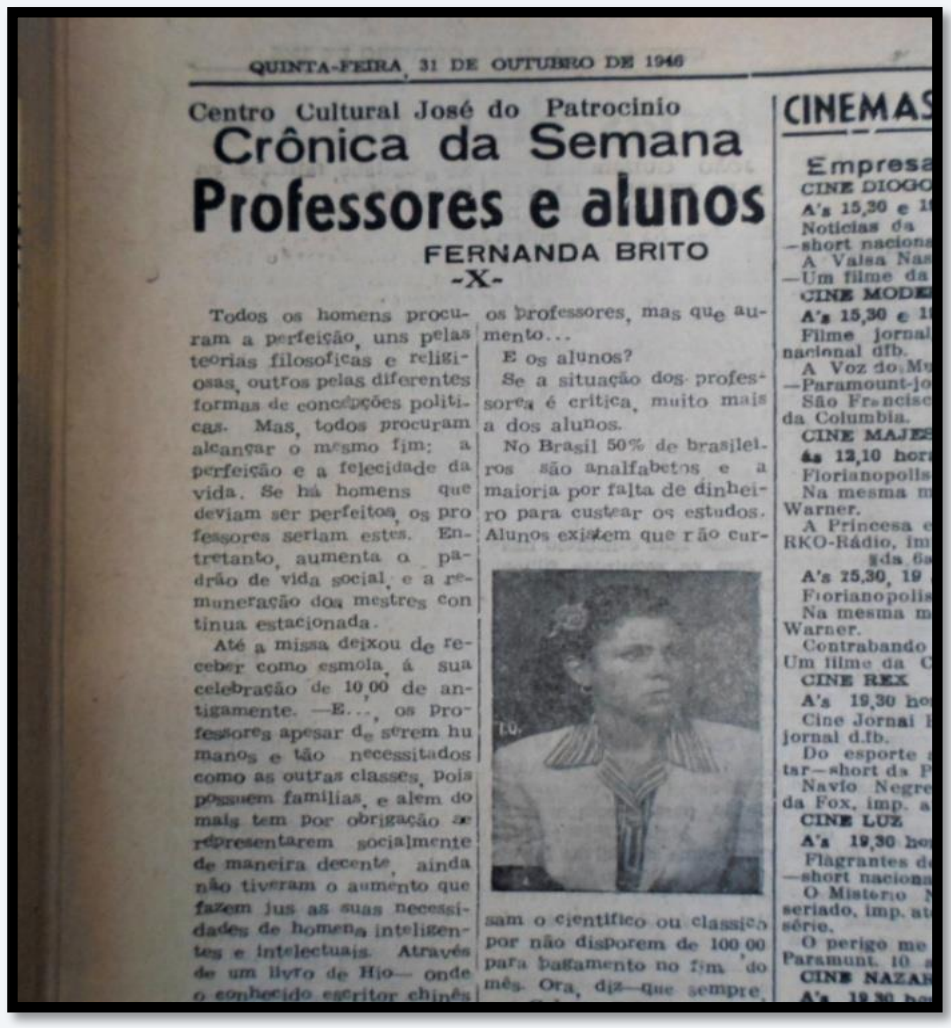

Fonte: GAZETA DE NOTÍCIAS. Fortaleza, p. 5, 13 out.1944. 
Próximo ao fim da circulação da coluna Ensino e Educação, em 1950, o Prof. Antonio Coelho Sampaio chama a atenção dos seus leitores para as condições de trabalho da sua profissão.

Raro é portanto, o professor que pode dedicar-se apenas ao magisterio, porque o ordenado que recebe não é suficiente para sua manutenção. Resultado: os melhores professores procuram obter um 'gancho' em qualquer repartição publica, afim de preencher uma parte do expediente com algo mais lucrativo. E assim fazendo, não tem mais tempo para o estudo. Não há, desse modo, professores especializados como outrora. Como poderá mesmo o professor particular obter o tempo necessario para o estudo, nas suas materias preferidas, se tem de ganhar a vida de varias maneiras? Conheço muitos colegas que tem dois ou três empregos para poder manter a familia: pela manhã - aulas; á tarde - emprego publico; de noite - trabalhando num escritorio, ou na imprensa. Onde está o tempo para especialização, para o estudo? E ainda mesmo que houvesse, onde arranjar dinheiro para comprar livros? (SAMPAIO, 1950, p. 3)

No trecho citado, o autor expõe dois problemas principais atrelados aos livros e à leitura no cotidiano professoral: 1) A falta de tempo para leitura e aperfeiçoamento da literatura necessária ao magistério, devido à má remuneração, o que gera a necessidade de o professor lançar-se em empregos auxiliares, para complementar a renda. 2) A falta de dinheiro para se comprarem livros, fossem eles necessários aos seu trabalho ou com fins recreativos. Ambos descortinam um cenário de precarização do trabalho docente, que permeia o magistério desde o início de sua existência.

O contexto presente no fragmento complexifica o problema da precarização salarial dos professores naqueles dias, na medida em que traz a seguinte informação: a falta de dinheiro para adquirir livros não era concernente apenas ao profissional docente. A par da dificuldade de atualizar-se e aperfeiçoar-se profissionalmente, por meio da literatura pedagógica, havia também empecilhos financeiros para subsidiar materiais didáticos dos filhos dessa classe laboral.

Quando Antonio Coelho Sampaio e a Profa Fernanda Brito reclamam sobre a dificuldade de acesso a livros - fosse em bibliotecas públicas ou na intenção de adquiri-los bem como dissertam sobre as dificuldades que passaram para conseguir brechas na rotina professoral para estudos, é sinalizada uma demanda: a de que talvez esses professores considerassem que a sua formação não seria estática e que, mesmo depois de diplomados, eles precisariam continuar comprando livros e atualizando seus conhecimentos. 


\section{Entre o bom e o mau: o que poderiam significar as ditas "más leituras" no Ceará no período de 1946 a 1950 ?}

Antonio Coelho Sampaio, em outro escrito publicado em 1948, reincide na temática da leitura, deixando explícito, no título, a advertência para os seus leitores: Cuidado com a leitura.

Fazendo um parêntesis sobre o assunto anterior, de defesa da classe, quero voltar ao fio da meada de antecedente. É que nunca será demais falar-se sobre a influencia perniciosa da má leitura, da leitura de certas revistas que circulam presentemente, entre as crianças e jovens. Ora, se a "leitura é considerada como o melhor meio de enriquecer a experiencia, porque por ela podem-se tirar do livro os conhecimentos nele acumulados" - expressão de um educador - não podemos deixar que continue essa influencia a perdurar no seio da infancia, dessa mesma infancia em que repousam todas as nossas esperanças do porvir. A leitura é responsável pela formação de muitos hábitos mentais. E esses hábitos podem ser, de acordo com a especie de leitura, bons ou maus. Desse modo, se fazemos uma verdadeira higiene da leitura, escolhendo, selecionando, o que vamos ler, estamos, com certeza, alicerçando uma boa base de conhecimentos que nos serão uteis para o futuro. Entretanto, se, ao contrário, permitirmos que nos apresentem para ler obras que, a cada passo, estão evidenciando o seu caráter de amoralidade, de perversão dos costumes, de traição aos deveres civicos e humanos, de exemplos francos da prática de crimes, que especie de hábitos estaremos forjando em nós mesmos? Será facil concluir... [...] (SAMPAIO, 1950, p. 3)

No trecho citado, é possível notar a assiduidade do autor em relação à coluna, visto que o ato de romper a continuidade do assunto do número passado e avisar isso ao leitor indica o horizonte de serialização e continuidade que se exige de uma seção fixa em um jornal.

Ao longo dos anos de circulação da coluna Ensino e Educação, observou-se uma maior recorrência nos assuntos relativos à infância e ao Ensino Primário, por se considerar que as crianças reproduziriam, com maior facilidade, os ditos bons exemplos. Havia a crença de que a imitação seria característica própria dessa etapa do desenvolvimento humano. Desse modo, a construção dos argumentos que buscavam diagnosticar uma suposta utilidade benéfica ou maléfica da leitura estava interligada com a própria noção de infância em voga na época. Toda a tônica desse discurso resultaria na crença de que essas crianças e esses jovens leitores seriam capazes de construir um futuro social distinto.

O objeto de destaque é, uma vez mais, a leitura entendida como portadora de potencialidades influenciadoras na mente humana e, em especial, na mente infantil e juvenil. Novamente, há a explicitação de valorações positivas e negativas para as leituras que 
circulavam naquele momento. Embasado por uma premissa, referida vagamente como de autoria de um educador, aparece nesse artigo um elemento importante: ambições higienizadoras da leitura.

Essa dita higiene da leitura, nessa coluna, está melhor detalhada. Segue-se ao raciocínio de que a leitura, por influir na mentalidade humana, forjaria hábitos e costumes. Assim, o apelo para conseguir adesões ao maniqueísmo dos argumentos que compõem esses raciocínios centra-se no futuro. Com a finalidade de proibir leituras vistas como más e fomentar as vistas como boas, tem-se, como recurso, o artifício de incutir crenças de medo do futuro ou, mais especificamente, das gerações futuras. Assim, a leitura, segundo o pensamento de Coelho Sampaio, não seria guiada pelos interesses do leitor, mas pela criação desses padrões que poderiam ser vistos como perniciosos ou morais. Vê-se, em suma, que o quesito autonomia leitora foi desconsiderado por Sampaio.

É possível perceber que toda essa argumentação que busca diagnosticar leituras como boas ou más está intimamente ligada com a noção de infância, embasada, sobretudo, no entendimento de que o ser infantil era movido pelas engrenagens da imitação. Isso resultaria em raciocínios vigiadores do mundo social, acreditando-se, em função disso, estar-se construindo um bom futuro. Desse modo, as preocupações recorrentes e negativas sobre aquele momento presente pareciam estar regidas pelo medo do futuro.

No artigo cujo trecho foi citado acima, Coelho Sampaio indica três livros da autoria de José Munhoz aos leitores da coluna Ensino e Educação: Contabilidade Aplicada, O Datilografo Correspondente em sua Casa e Metodo de Datilografia. Novamente é possível rastrear aspectos da rede de relações do autor, quando ele mesmo afirma ter conhecido José Munhoz recentemente ao período de escritura daquele número da coluna; Sampaio ainda explicita o cargo de Munhoz, na época, Diretor do Instituto Nacional de Ensino de São Paulo e, além disso, informa o endereço da instituição citada. Poucas vezes, na coluna, existiram autores tão bem circunstanciados por Coelho Sampaio.

Daí se conclui que, para Sampaio, os livros de José Munhoz seriam exemplos de leituras consideradas como boas. E, pelo tema desses livros, é possível notar um contraste com a problemática da dita má leitura, sendo importante destacar, portanto, que o que ele considera como má leitura, conforme indica mais uma vez o trecho acima, seriam os ditos conteúdos perversores, imorais, acívicos, fazendo contraponto com os bons livros, isto é, disciplinadores, morais, cívicos. Ou seja, os livros de José Munhoz, por seus assuntos contabilidade e datilografia - não parecem manter relações com os pilares defendidos por 
Coelho Sampaio como leituras boas nem como leituras más. Os critérios de indicação ao público com base em seu diagnóstico - bom ou mau - mais parecem ser construídos a partir de pilares de outra ordem, mais afeitos às relações de sociabilidade do autor.

Coelho Sampaio também chamou a atenção para o que seria uma deturpação dos meios de comunicação e do avião, veículos unidos pelos seus intentos de fazer disseminar ideias. Esses teriam se transformado em três características: disseminadores da morte, de ideologias perigosas e de péssimos costumes. Essa primeira, mais relacionada aos aviões, mantém relações diretas com a Segunda Guerra Mundial, que estava bastante presente no imaginário social naquele momento. No que concerne ao que seriam as ideologias perigosas e aos péssimos costumes, trata-se de ideias mais nuançadas, que necessitam ser problematizadas.

É importante destacar a forma com que o autor se reporta a esses assuntos no início da coluna, antes de desenvolver os temas propostos: "Conforme tenho aludido em artigos anteriores (...)", ou seja, isso indica certa intenção de integrar as séries dos assuntos abordados na coluna, na medida em que raramente um assunto que orbita o tema maior Ensino e Educação é abordado em um só número da publicação.

No penúltimo número da coluna Ensino e Educação, intitulado Um Novo Aspecto da Leitura, em janeiro de 1950, Coelho Sampaio ainda estava destinado a ponderar sobre o assunto da leitura. $\mathrm{O}$ foco das preocupações relativas a esse tema é o ser infantil:

Daí a importancia na escolha da leitura, do cuidado nos hábitos e sistema de nosso 'modus-vivendi', ao convivio com as crianças. (...) É portanto, muito acentuada a orientação que pode ser dada á infancia, por meio da leitura. Devia ser, pois, objeto de maior cuidado, por parte dos autores, a escolha dos assuntos para seus livros. Adotados nas escolas do país, os exemplos ali citados podem influir grandemente no patriotismo, na conduta e na moral dos educandos. Pensando bem nesse aspecto da leitura, li, há poucos dias, a nova coleção de livros de leitura para o Curso Primário, editada pela EDITORA DO BRASIL, S/A, de autoria dos Profs. DOMINGOS BARROSO e RITA TOMAZ BARROSO. São obras que merecem a atenção dos que se dedicam ao ensino primário. Pela feição, inteiramente nova, que foi dada ao assunto de suas lições, demonstram possuir temas capazes de despertar verdadeiro patriotismo dos educandos. Além disso, possuem um aspecto novo e intrinseco: são lições vasadas em termos ao alcance da criança. Nada impede á inteligencia infantil, para alcançar o que encerram suas páginas. O que se vê, nos seus capítulos artisticamente ilustrados, são temas proprios do meio em que vive a criança: brinquedos, frutas, objetos, lugares, o lar. Nada ali se estampa de maneira a encher o espirito infantil de crendices abstratas, nem de ambientes ricos de fantasias. Tão pouco se procura mostrar aos leitores mundos distantes e desconhecidos. Tudo ali é Brasil. Ali a criança sente, mais de perto, a realidade de sua vida, da vida de 
seus pais, conhecendo tambem os reais problemas que assoberbam a familia, o sertão, o estado e a propria nacionalidade. (SAMPAIO, 1950,p. 3)

Embora Coelho Sampaio tenha se referido a uma coleção de livros de leitura, tivemos acesso apenas a um desses livros, chamado A Criança do Brasil, publicado pela Editora do Brasil S/A. (BARROSO; BARROSO, 1950). Foi possível rastrear, a partir da coluna acima, critérios necessários para uma boa leitura, segundo sua visão. Isso ocorre porque essas obras são um dos poucos citados em seus escritos referentes a livros que constam como indicação positiva.

Os parâmetros avaliativos do material eram pautados em dois pilares: conteúdos nãoficcionais e, principalmente, assuntos que despertassem o sentimento patriótico, que reforçassem laços de identidade com o país. Afirmar que "tudo ali é Brasil", como sendo um grande trunfo dos livros, significa afirmar que, quanto mais o livro didático tratasse de narrativas pertencentes ao sentimento de brasilidade, tanto mais ele seria qualificado como bom. Expõe-se, como sendo natural, o entrelaçamento entre o ato de ler e o patriotismo.

O livro A Criança do Brasil é composto por 73 lições curtas e ilustradas. Algumas delas são mais diretamente de caráter informativo e outras no formato de histórias. Ao fim, existem questionários com perguntas que enfatizam conteúdos que os autores reforçaram de maneira mais pungente nas lições. Nessa obra, há muitas seções que se destinam a trazer à tona as temáticas do ruralismo e da agricultura. É posto como finalidade maior do cidadão brasileiro ser útil ao campo, na função de trabalhador rural. Para isso, existem muitas lições que traçam elos entre o amor ao Brasil e o amor ao ambiente ruralista. Os conteúdos didáticos deveriam conter, para Coelho Sampaio, elementos que fizessem parte do cotidiano da criança, de modo a incentivá-la a amar o local em que nasceu. Essa obra está na perspectiva da literatura infantil brasileira que buscava a retomada de consciência [ou tê-la] da própria nação e seus valores legítimos para uma formação cultural (ARROYO, 2011).

\section{Considerações finais}

Quaisquer que sejam os aspectos examinados que tangenciam acerca dos livros e da leitura, neles há complexidade, já que ler, em quaisquer suportes, não é um ato naturalizado e atemporal. A história da leitura resguarda elementos que, muitas vezes, têm como linha de chegada apenas hipóteses. Os leitores do tempo de outrora e de agora têm suas particularidades, peculiaridades e autonomia. 
A prática de (re)pensar constantemente os procedimentos de análise ou os refinamentos metodológicos presentes na forma de se interpretarem realidades históricas e de se construir uma narrativa, como resultado do fazer histórico, deve permear todo o estudo. Isso ocorre porque o acesso do pesquisador ao passado se processa de forma mediada. A matéria prima à qual se tem acesso, as fontes, expressam sempre diferentes visões sobre uma realidade, ou seja, jamais se apreenderá uma totalidade desse prisma social. Em razão disso, faz-se necessário enxergar esses vestígios documentais sob a ótica do problema, desnaturalizar o que se impõe como regra/padrão, refinando-os a partir de sua heterogeneidade, e não polarizações.

Destacamos que o presente estudo atentou-se à problemática do lugar social e do lugar de fala de Antonio Coelho Sampaio em um jornal de grande circulação, como foi a Gazeta de Notícias, no Ceará dos anos 1940. Na condição de economista, líder estudantil, articulista, professor e proprietário de um estabelecimento de ensino privado em Fortaleza, o autor se apropria de seu lugar privilegiado e nos permite compreender a construção de um discurso de autoridade autocentrado e autoatribuído.

Ao se investigar as orientações acerca do livro e da leitura, veiculados pelo Prof. Antônio Coelho Sampaio na coluna Ensino e Educação no Ceará dos anos 1940, finalidade principal deste artigo, observou-se que há mais uma preponderância de discursos acerca das leituras pretensamente proibidas, valoradas como más, vis e amorais, do que propriamente orientações sobre o que se deveria ler, de acordo com suas acepções educativas. Quando essas indicações de leituras consideradas positivas constam na coluna, estas, de modo geral, fazem referência a leituras ditas úteis, ou seja, a serviço do mercado de trabalho no período em análise, de um Brasil historicamente situado, que buscava se desenvolver economicamente em uma perspectiva industrial.

Cuidado com a leitura, conforme o subtítulo de um dos números da coluna, homônimo ao título do presente escrito, atine ao rastro de uma compreensão de leitura que a identificava como alicerce de uma formação de pensamentos e hábitos nos indivíduos leitores. O tom de advertência dizia respeito à máxima de ler para se exemplar ou ler para se imitar. A pretensa higienização da leitura propalada por Coelho Sampaio acreditava em uma relação direta entre o hábito de ler e implicações no futuro social. 


\section{REFERÊNCIAS}

ARROYO, Leonardo. Literatura infantil brasileira. 3ed. rev. e ampliada. São Paulo: Editora Unesp, 2011.

BARROSO, D., BARROSO R. T. A Criança do Brasil - Terceiro Livro. Coleção Didática Infantil. Série Setentrional. Vol. IV. Editora do Brasil S/A. 1950.

BRITO, Fernanda. Crônica da semana. Professores e alunos. Gazeta de Notícias, Fortaleza, p. 3, 31 out. 1946.

CAPELATO, Maria Helena Rolim. Imprensa e história do Brasil. São Paulo: Contexto, 1988.

CHARTIER, Roger. A história cultural: entre práticas e representações. Lisboa: Difel/Rio deJaneiro: Bertrand. 1989.

DE LUCA, Tania Regina. História Dos, Nos e Por Meio dos Periódicos. In: PINSKY, Carla Bassanezi. Fontes Históricas. São Paulo: Contexto, 2005.

GAY, Peter. O Coração desvelado. São Paulo: Companhia das Letras, 1999, p. 168-243.

GAZETA DE NOTÍCIAS. Fortaleza, p. 5, 13 out.1944.

Guzmán Méndez, D.P., \& Marín Colorado, P.A. (julio-diciembre de 2016). Lectores y textos escolares durante la primera mitad del siglo XX en Colombia. La Palabra, (29), 185-197. Disponível em: <http://www.scielo.org.co/pdf/laplb/n29/n29a12.pdf>. Acesso em: 12 dez. 2018.

KRAVETZ, Marc. Os jornalistas « fazem »a História. In Duby, George et al. História e Nova História. Lisboa: Teorema, 1986.

NOBRE, Geraldo. Introdução à História do Jornalismo Cearense. Fortaleza, Grecel, 1976.

RAMALHO, Braulio Eduardo Pessoa. Foi assim! O Movimento Estudantil no Ceará (1928 1968). Rio - São Paulo - Fortaleza: ABC Editora, 2002.

SAMPAIO, C. Ensino e educação. Gazeta de Notícias, Fortaleza, p. 3, 27 jul. 1948.

SAMPAIO, C. Ensino e educação: um novo aspecto da leitura. Gazeta de Notícias, Fortaleza, p. 3, 14 jan. 1950.

SAMPAIO, Coelho. Educação. Gazeta de Notícias, Fortaleza, p. 3, 12 fev. 1950.

SAMPAIO, Coelho. Ensino e educação - O problema do professor particular. Gazeta de Notícias, Fortaleza, p. 3, 25 jan. 1950. 


\section{SOBRE AS AUTORAS:}

\section{Manuelle Araújo da Silva}

Doutoranda em Educação pela Universidade Federal da Paraíba (UFPB). Mestre em História Social pela Universidade Federal do Ceará (UFC) e Membro do Grupo de Pesquisa: História e Documento: reflexões sobre fontes históricas. E-mail: manuelle.araujosilva@yahoo.com.br.

(iD http://orcid.org/0000-0003-4701-2589

\section{Fabiana Sena}

Doutora em Letras pela Universidade Federal da Paraíba (UFPB). Pós-doutorado em Educação pela Universidade Estadual do Rio de Janeiro (UERJ). Departamento de Metodologia da Educação. Programa de Pós-Graduação em Educação. Líder do Grupo de Pesquisa Memória, História e Educação. E-mail: fabianasena@yahoo.com.br.

(iD http://orcid.org/0000-0002-3340-7769

\section{Mariza Silva de Araújo}

Doutora em Educação pela Universidade Federal da Paraíba (UFPB). Instituto de Educação Superior Presidente Kennedy (IFESP), Coordenadora do Núcleo Memória e Documentação do IFESP. Membro do Grupo de Pesquisa Memória, História e Educação. E-mail: mariza@ifesp.edu.br.

iD http://orcid.org/0000-0002-5322-306X

Recebido em: 13 de agosto de 2019

Aprovado em: 27 de novembro de 2019

Publicado em: 20 de janeiro de 2020 